\title{
Lyon 5e « Ludgunum »
}

51, rue des Aqueducs

\section{Cécile Ramponi}

\section{(2) OpenEdition}

12 Journals

Édition électronique

URL : http://journals.openedition.org/adlfi/6970

ISSN : 2114-0502

Éditeur

Ministère de la culture

Référence électronique

Cécile Ramponi, « Lyon 5e "Ludgunum » », ADLFI. Archéologie de la France - Informations [En ligne], Rhône-Alpes, mis en ligne le 01 mars 2007, consulté le 21 avril 2019. URL : http:// journals.openedition.org/adlfi/6970

Ce document a été généré automatiquement le 21 avril 2019.

(C) Ministère de la Culture et de la Communication, CNRS 


\title{
Lyon 5e « Ludgunum »
}

\author{
51 , rue des Aqueducs
}

\section{Cécile Ramponi}

\section{Identifiant de l'opération archéologique : 229678}

Date de l'opération : 2007 (EX)

1 Ce diagnostic archéologique porte sur le tracé supposé d'une section aérienne de l'aqueduc antique de la Brévenne.

2 Au total, sur les sept sondages ouverts, un seul a permis de mettre en évidence quatre des piles de l'ouvrage (Fig. $n^{\circ} 1$ : Plan). Elles se succèdent selon un rythme assez régulier, d'ouest en est, avec un entraxe de 3,80 $\mathrm{m}$ à $3,90 \mathrm{~m}$ pour un plan rectangulaire à carré de $1,80 \mathrm{~m}$ à $2 \mathrm{~m}$ de côté. Les restes de maçonneries, partiellement détruits par les canalisations et le mur d'une maison contemporaine, se présentent sous la forme d'un blocage d'éclats de gneiss pris dans un mortier rosé, bourré en tranchée étroite. Aucun reste des élévations ne subsiste. Le $n^{\circ} 51$ se situe à égale distance de l'arrivée du siphon des Massues (Tassin-la-Demi-Lune), encore partiellement visible au bout de la même rue, et des négatifs de piles trouvés en sondage au n ${ }^{\circ} 10$ de la même rue (diagnostic: Ayala, 1994) et au 70 avenue du Point-du-jour (diagnostic : Cécillon, 2001).

3 Aucun niveau de sol ou aménagements liés à la construction de l'ouvrage ne semble conservé. De même, aucune occupation ancienne n'a été retrouvée dans les autres sondages sur cette parcelle.

RAMPONI Cécile 


\section{ANNEXES}

Fig. $n^{\circ} 1$ : Plan
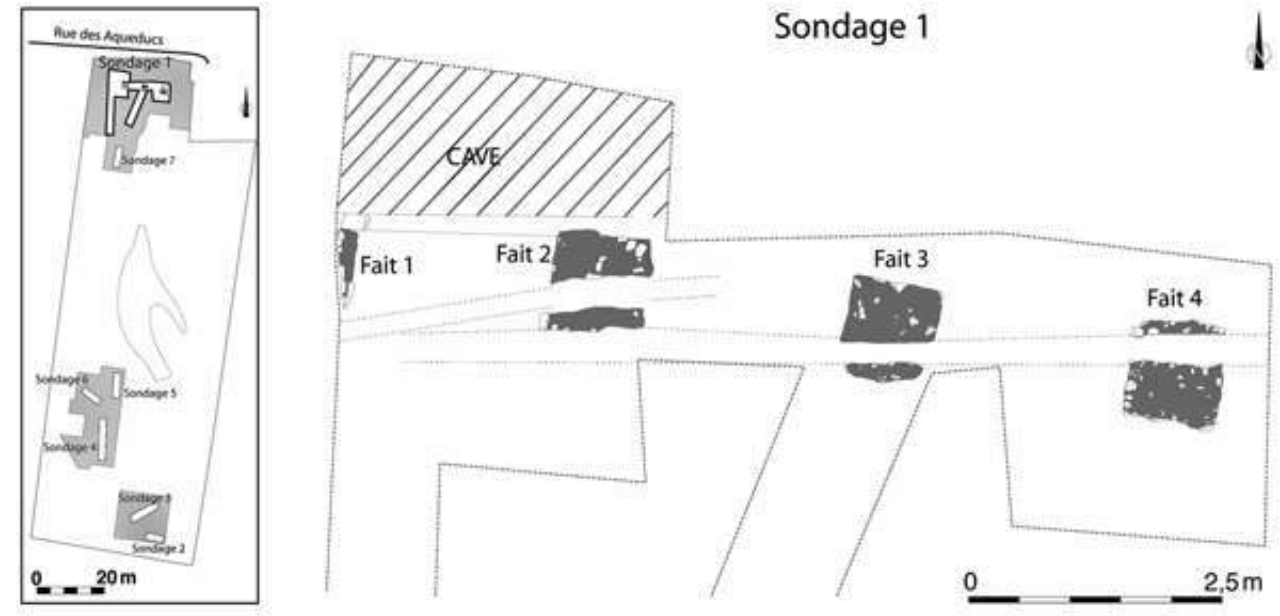

Auteur(s) : Ramponi, Cécile. Crédits : ADLFI (2007)

INDEX

Index chronologique : Antiquité romaine

Index géographique : Rhône-Alpes, Rhône, Lyon

operation expertise (EX)

\section{AUTEURS}

\section{CÉCILE RAMPONI}

